\title{
Hemithyroidectomy: Papillary Thyroid Carcinoma in Low Risk Group Patients
}

\author{
Islam MA ${ }^{1}$, Mohammed $\mathrm{T}^{2}$, Mamoon $\mathrm{TB}^{2}$, Chowdhury $\mathrm{NH}^{3}$, Khan $\mathrm{SR}^{4}$, Rahman $\mathrm{ASML}^{5}$ \\ ${ }^{1}$ Md. Ashraful Islam, Professor and Head, Otolaryngology-Head \& Neck Surgery, Bangladesh Medical College \\ 2 Tareq Mohammad, Assistant Registrar, ENT, Bangladesh Medical College \\ ${ }^{3}$ Nazmul Hossain Chowdhury, Assistant Professor, ENT, Bangladesh Medical College \\ ${ }^{4}$ Towsif Bin Mamoon, Assistant Registrar, ENT, Bangladesh Medical College \\ ${ }^{5}$ Saif Rahman Khan, Assistant registrar, ENT, National Institute of ENT \\ ${ }^{6}$ ASM Lutfur Rahman, Resident Surgeon, Bangladesh Medical College Hospital
}

Abstract

\section{$>$ Background \& Objectives:}

Papillary thyroid cancer (PTC) is the most prevalent histologic subtype of thyroid cancer accounting for more than $80 \%$ of all cases. A single size threshold of $4 \mathrm{~cm}$ maximized prognostic discrimination with tumors $>4 \mathrm{~cm}$ associated with a five times higher risk of recurrence than those $\leq 4 \mathrm{~cm}$. The purpose of this present study was to determine an effective treatment strategy for patients with small unilateral papillary thyroid carcinoma in a low risk group below tumor size $\leq 4 \mathrm{~cm}$.

\section{$>$ Material and Methods:}

This is a prospective study of 300 patients who were diagnosed as papillary thyroid carcinoma by preoperative FNAC or postoperative histopathology. The age of the patients' was ranged between 15 to 45 years. The criteria were: tumor $\leq 4 \mathrm{~cm}$, unilateral involvement, cytological non-aggressive subtype, absence of lymph node involvement and extra thyroidal extension on ultrasonography and absence of clinical distant metastases. The study was conducted in tertiary care hospital in Bangladesh from 1989 to 2019. .

\section{$>$ Results:}

300 patients were included in the study, 267 patients $(89 \%)$ did not show any recurrence of disease. 33 patients $(11 \%)$ came with locoregional recurrence of disease in clinical and USG findings without any distant metastasis. Maximum patients were between the ages 31-40 year followed by 21 -30 year. Female was out number male in the ratio

\section{Conclusion:}

This study can lead to a result that hemi thyroidectomy is now-a-days a better surgical option for PTC even up to tumor size of $\leq 4 \mathrm{~cm}$.

Keywords:- Thyroid Papillary Carcinoma, HemiThyroidectomy, Size, Recurrence.

\section{INTRODUCTION}

Over the past 20 to 30 years there has been an increase in the incidence of thyroid cancers in whole world ${ }^{1-4}$. The majority of the new thyroid cancer cases are small papillary thyroid cancers (PTCs).

There has been a long unresolved debate in the literature with regard to the optimal initial treatment for unilateral papillary thyroid cancer (PTC), including the extent of thyroidectomy ${ }^{5-8}$. The correct approach to treat low-risk intra thyroidal papillary thyroid carcinoma (PTC) is still controversial. The traditional paradigm of treating all patients with thyroid cancer with total thyroidectomy, radioactive iodine (RAI), and suppressive thyroid hormone therapy is no longer suitable. Rather, patients with thyroid cancer should receive treatment depending on the size of the tumor, nodal involvement and age of the patient.

The role of hemi thyroidectomy as a treatment option for low-risk tumors has expanded on the role of active surveillance. Previously, hemi thyroidectomy was only indicated for unifocal tumors $<1 \mathrm{~cm}$ in size without preoperative evidence of extra thyroid extension or lymph node metastases $\left(\mathrm{N}_{0}\right)$. More recent evidence however, suggests that hemi thyroidectomy can be safely performed in patients with larger tumors. Publication of a sentinel study in 2007 by Bilimoria ${ }^{9}$ based on the NCDB database showed that recurrence was slightly but statistically higher $(9.8 \%$ vs. $7.7 \%)$ and survival was slightly lower $(97.1 \%$ vs. $98.4 \%$ ) in lobectomy patients vs. bilateral resection. However, lobectomy had been shown to be equivalent to near-total (NTTx) or total thyroidectomy (TTx) in survival in T1-2 N0 patients in publications from Memorial Sloan Kettering Cancer Center ${ }^{10}$.

The controversy has been re-kindled by two recent publications for PTC even as large as $4 \mathrm{~cm}^{11,12}$. The Japanese study reviewed over 1,000 patients who underwent lobectomy for tumors up to $4 \mathrm{~cm}$ in size, with a follow-up period of 17.6 years (without addition of RAI), in the absence of clinically positive lymph nodes or extra thyroidal extension where no patient died under 45 years of age. The American study re-analyzed 61,775 patients from the NCDB, and overall survival was similar in patients undergoing total thyroidectomy versus lobectomy for tumors $1-4 \mathrm{~cm}$ in size. 
PTC, even though the label of cancer is applied to these small tumors, with rare exception, they are biologically innocent. Even though spread to lymph nodes at surgical resection occurs in about $30 \% 13,14$, these metastasis are usually quite small and recurrence is seldom seen.

\section{$>$ Objective}

The purpose of the present study was:

- To determine an effective treatment strategy for patients with small unilateral papillary thyroid in a low risk group below tumor size $\geq 4 \mathrm{~cm}$.

\section{METHODS}

Study design: prospective study

Study sample: 300 patients

Sampling technique: Simple random sampling

Study period: 30 years (1989-2019)

Study places:

- Bangladesh Medical College Hospital

- Popular Medical College Hospital

- Combined Military Hospital, Dhaka

- Padma General Hospital

$>$ Inclusion criteria

- Tumor size $\leq 4 \mathrm{~cm}$

- Unilateral involvement

- Diagnosed as papillary thyroid carcinoma by preoperative FNAC or postoperative histopathology

- Cytological non-aggressive subtype

- Absence of lymph node involvement and extra thyroidal extension on ultrasonography

- Absence of clinical distant metastases

$>$ Exclusion criteria

- Patients unfit for surgeries

- Patients not giving consent

\section{$>$ Procedure}

Patients were included in the study according to the selection criteria. Each of the patients \& patients' attendants were thoroughly counseled regarding nature of disease, prognosis, surgical options, advantages \& disadvantages of each options and importance of regular follow-up.

All surgeries were done under general anesthesia. Transverse skin crease incision being made. Skin \& subplatysmal flap were elevated. Affected lobe of thyroid was mobilized. Recurrent laryngeal nerve and parathyroid glands were identified \& preserved in each case. After hemostasis wound closed in layers keeping 01 drain in situ. During anesthetic recovery, vocal cord movement was checked in every case.
Following surgery, patients were kept in close observation in post-operative ward. Drain was usually removed on $2^{\text {nd }}$ or $3^{\text {rd }}$ POD depending on amount $\&$ color of fluid in drain tube. After removal of drain patients were discharged from hospital and advised to come with histopathology report on $7^{\text {th }}$ POD.

$>$ Follow-up schedule

- After reviewing histopathology report patients were advised for follow-up monthly for first 03 months then every 03 months for next 06 months and yearly for the rest of their life.

- All patients had followed up by a median period of 25 months (range $=6$ to 166 months).

- During each visit they were advised to bring the test reports of $\mathrm{TSH}, \mathrm{FT}_{4}$, Thyroglobulin and patients were clinically examined.

\section{RESULT}

In our study total 300 patients were included. Among them 191 (63.67\%) were female \& 109 (36.33\%) were male shown in Table 1. Majority of the patients (46.67\%) were aged between 31 to 40 years. The youngest patient was 17 years old and the oldest being 43 years presented in Table 2.

Preoperative USG of each patient was done. All of them were unilateral involvement with tumor size $\geq 4 \mathrm{~cm}$.

$281(93.67 \%)$ patients were diagnosed as papillary thyroid carcinoma by pre-operative FNAC. Rests of the patients were initially diagnosed as benign tumor of thyroid. After surgery histopathology revealed papillary carcinoma (Table 3).

All patients had undergone hemi thyroidectomy without Radioactive Iodine Ablation and followed up by a median period of 25 months.

During follow up in addition to clinical examination following investigations were done routinely-

$>$ USG of neck with special attention to thyroid bed \& neck nodes

$>$ S.TSH

$>$ S. Thyroglobulin

Among 300 patients, 267 patients (89\%) did not show any recurrence of disease. 33 patients $(11 \%)$ came with locoregional recurrence of disease in USG findings with raised S.Thyroglobulin (Table 4). Amongst the recurrent 33 patients $24(73 \%)$ were female \& $9(27 \%)$ were male (Table $5)$. Recurrences were more frequent 15 patients $(45.45 \%)$ were between 31-40 years of age (Table 6). Completion thyroidectomy with Radioactive Iodine Ablation was done in recurrent cases. 
ISSN No:-2456-2165

\begin{tabular}{|c|c|c|}
\hline Sex distribution & Number of patients & \multicolumn{1}{c|}{$\%$} \\
\hline Female & 191 & 36.33 \\
Male & 109 & 100 \\
\hline
\end{tabular}

Table 1:- Sex Distribution of study population ( n 300)

\begin{tabular}{|c|c|c|}
\hline Age (Years) & Number of patients & 3.67 \\
\hline $11-20$ & 11 & 39.33 \\
$21-30$ & 118 & 46.67 \\
$31-40$ & 140 & 10.33 \\
$41-50$ & 31 & 100 \\
\hline
\end{tabular}

Table 2:- Age distribution of study population $(n=300)$

\begin{tabular}{|c|c|c|}
\hline Histodiagnosis & Number of patients & \multicolumn{1}{c|}{93.67} \\
\hline Papillary thyroid carcinoma & 281 & 6.33 \\
Nodular goiter & 19 & 100 \\
\hline
\end{tabular}

Table 3:- Preoperative diagnosis by FNAC (n 300)

\begin{tabular}{|c|c|c|}
\hline Result & Number of patients & $\%$ \\
\hline No recurrence & 267 & 89 \\
Recurrence & 33 & 11 \\
\hline & 300 & 100 \\
\hline
\end{tabular}

Table 4:- Result following hemithyroidectomy on follow-up (n300)

\begin{tabular}{|c|c|c|}
\hline Sex distribution & Number & $\%$ \\
\hline Male & 24 & 73 \\
Female & 9 & 27 \\
\hline
\end{tabular}

Table 5:- Sex distribution among recurrent cases (n 33)

\begin{tabular}{|c|c|c|}
\hline Age (Years) & Number & \multicolumn{1}{c|}{} \\
\hline $11-20$ & 3 & 39.09 \\
$21-3$ & 13 & 45.45 \\
$31-40$ & 15 & 6.06 \\
$41-50$ & 2 & 100 \\
\hline
\end{tabular}

Table 6:- Age distribution of recurrent cases n 33

\section{DISCUSSION}

It is evident that thyroid cancer rates are on the rise and is considered the most prevalent endocrine malignancy all over the world; and histologically mostly the papillary thyroid carcinoma ${ }^{15,16}$. Till to date, the treatment options remain in the dilemma to the extent of surgery in low risk PTC.

Thyroid surgery either total thyroidectomy or hemithyroidectomy should be performed by high-volume surgeons ( $>25$ thyroid surgeries yearly) to avoid surgical complications $^{17-19}$. In our series it is experienced that hemithyroidectomy is appropriate for low-risk thyroid cancer to prevent recurrence. It is more than ever essential to explain the merits/demerits of the modalities of surgery i.e. total thyroidectomy versus hemithyroidectomy in presence of the patients/attendants. So they can be well aware themselves fully in a conversation around what is the best modalities of surgery. In our study, each of the patients \& patients' attendants were thoroughly counseled regarding nature of disease, prognosis, surgical options, advantages \& disadvantages of each options and importance of regular follow-up.

It has been observed in the published literature so far that patients with thyroid cancer $>1 \mathrm{~cm}$ and $\leq 4 \mathrm{~cm}$ without extrathyroidal extension, without clinical evidence of any lymph node metastases, the initial surgical procedure can be either a near-total/total thyroidectomy or a lobectomy ${ }^{20-}$ 23. The higher surgical risks e.g. transient or permanent post-surgical hypo parathyroidism, recurrent laryngeal nerve injury unilateral or bilateral, hematoma formation, infection are documented in total or near total thyroidectomy especially in the hands of inexperienced surgeons. These patients need lifelong thyroid hormone replacement and postoperative radioiodine ablation (RAI) ${ }^{24-}$ 25. A study by Popadich et al found that the addition of 
routine central lymph node dissection with thyroid surgery in patients in $\mathrm{cNO}$ papillary thyroid carcinoma reduced the need for reoperation in the central compartment and was associated with lower postoperative thyroglobulin levels ${ }^{26.27}$.

In this study, hemithyroidectomy was carried out in all 300 patients and no patient had developed any perioperative or postoperative surgical complications. The only drawback experienced after surgery was regarding their biochemical follow-up; therefore, the follow-up mostly relied on clinical assessment and ultrasonography findings. In this series, locoregional recurrence was found in only 33 cases $(11 \%)$ who needed second surgery which is also shown in other study ${ }^{28,29}$. There was no evidence of distant metastasis noted in those recurrent patients on our follow up.

A follow-up for 6 years in low risk PTC hemithyroidectomy patients done by Siassakos et al in 2008 and identified no recurrence, metastases or mortalities. The authors concluded that in this sample of patients with PTC, no further surgical or radiotherapeutic intervention was warranted $^{26-28}$. Another similar study showed in 281 PTC patients where only $3.9 \%$ developed locoregional recurrence, and a single patient had lung metastasis ${ }^{29,30}$. In this study, at the time of final follow-up with a median of 7 years, $89 \%$ were free of disease and $11 \%$ had recurrence who underwent second surgery which correlates almost similar result cited in the above observation.

Total thyroidectomy with RAI and lifelong thyroid hormone replacement had increased chance of developing complications. On the other hand, hemithyroidectomy does not need RAI and hormonal replacement thus reduce the cost/extra burden in the developed and developing country.

Though further large scale study should require to determine the optimal treatment option for low risk PTC, but this study can lead to a result that hemithyroidectoy is at the present days considered as a better surgical modality even up to tumor size of $\leq 4 \mathrm{~cm}$. In this study locoregional recurrence was found in only $11 \%$ cases without any evidence of distant metastases. It is found here that recurrences were more frequent $45.45 \%$ between the ages of 41 to 45 year and less frequent in the ages 31 to 40 year.

Follow up by serial USG is one of the most important parameters in hemi thyroidectomy patients of PTC.

\section{CONCLUSION}

A papillary thyroid carcinoma equal or less than $4 \mathrm{~cm}$, confined to unilateral thyroid lobe with no lymph node involvement or extra thyroidal extension and in the absence of distant metastases, hemithyroidectomy is the treatment of choice. Surgical options and importance of postoperative follow up details should be discussed clearly to the patients before embanking to surgery.

\section{REFERENCES}

[1]. Davies L, Welch HG. Current thyroid cancer trends in the United States. JAMA Otolaryngol Head Neck Surg 2014; 140: 317-22.

[2]. Davies L, Morris LG, Haymart M, Chen AY, Goldenberg D, Morris J, et al. American Association of Clinical Endocrinologists and American College of Endocrinology disease state clinical review: the increasing incidence of thyroid cancer. Endocr Pract 2015; 21:686-96.

[3]. Vaccarella S, Dal Maso L, Laversanne M, Bray F, Plummer M, Franceschi S. The impact of diagnostic changes on the rise in thyroid cancer incidence: a population-based study in selected high-resource countries. Thyroid 2015; 25:1127-36.

[4]. Vaccarella S, Franceschi S, Bray F, Wild CP, Plummer M, Dal Maso L. Worldwide thyroid-cancer epidemic? The increasing impact of overdiagnosis. $\mathrm{N}$ Engl J Med 2016; 375: 614-7.

[5]. Buckwalter JA and Thomas CG Jr: Selection of surgical treatment for well differentiated thyroid carcinomas. Ann Surg 1972; 176: 565-568.

[6]. Christensen SB, Ljungberg O and Tibblin S: Surgical treatment of thyroid carcinoma in a defined population: 1960 to 1979 . Evaluation of the results after a conservative surgical approach. Am J Surg 1983; 146: 349-354.

[7]. Demeure MJ and Clark OH: Surgery in the treatment of thyroid cancer. Endocrinol Metab Clin North Am1990; 19: 663-683.

[8]. Friedman M and Pacella BL Jr: Total versus subtotal thyroidectomy: arguments, approaches and recommendations. Otolaryngol Clin North Am 1990; 23: 413-427.

[9]. Bilimoria KY, Bentrem DJ, Ko CY, et al. Extent of surgery affects survival for papillary thyroid cancer. Ann Surg 2007; 246:375-81.

[10]. Nixon IJ, Ganly I, Patel SG, et al. Thyroid lobectomy for treatment of well differentiated intrathyroid malignancy. Surgery 2012; 151:571-9.

[11]. Matsuzu K, Sugino K, Masudo K, et al. Thyroid lobectomy for papillary thyroid cancer: long-term followup study of 1,088 cases. World J Surg 2014; 38:68-79.

[12]. Adam MA, Pura J, Gu L, et al. Extent of surgery for papillary thyroid cancer is not associated with survival: an analysis of 61,775 patients. Ann Surg 2014; 260:601-5; discussion 605-7.

[13]. Hay ID, Hutchinson ME, Gonzalez-Losada T, et al. Papillary thyroid microcarcinoma: a study of 900 cases observed in a 60-year period. Surgery 2008; 144:980-7.

[14]. Chow SM, Law SC, Chan JK, et al. Papillary microcarcinoma of the thyroid-Prognostic significance of lymph node metastasis and multifocality. Cancer 2003; 98:31-40. 
[15]. Geron Y, Benbassat C, Shteinshneider M, Koren S, Markus E, Hirsch D, Kalmovich LM. Long-Term Outcome after Hemithyroidectomy for Papillary Thyroid Cancer: A Comparative Study and Review of the Literature. Cancers (Basel) 2019 Jan; 11(1): 26

[16]. Jatin P.S. Thyroid Carcinoma: Epidemiology, Histology, and Diagnosis. Clin Adv Hematol Oncol. 2015 Apr; 13(4 Suppl 4): 3-6.

[17]. Adam MA, Thomas S, Youngwirth L, Hyslop T, Reed $\mathrm{SD}$, Scheri RP, et al. Is there a minimum number of thyroidectomies a surgeon should perform to optimize patient outcomes? Ann Surg 2017;265:402-7.

[18]. Al-Qurayshi Z, Robins R, Hauch A, Randolph GW, Kandil E. Association of surgeon volume with outcomes and cost savings following thyroidectomy: a national forecast. JAMA Otolaryngol Head Neck Surg 2016; 142:32-9.

[19]. Youngwirth LM, Adam MA, Scheri RP, Roman SA, Sosa JA. Patients treated at low-volume centers have higher rates of incomplete resection and compromised outcomes: analysis of 31,129 patients with papillary thyroid cancer. Ann Surg Oncol 2016; 23:403-9.

[20]. Padovani R.P., Robenshtok E., Brokhin M., Tuttle R.M. Even without additional therapy, serum thyroglobulin concentrations often decline for years after total thyroidectomy and radioactive remnant ablation in patients with differentiated thyroid cancer. Thyroid. 2012; 22:778-783.

[21]. Shah J.P., Loree T.R., Dharker D., Strong E.W. Lobectomy versus total thyroidectomy for differentiated carcinoma of the thyroid: A matchedpair analysis. Am. J. Surg. 1993;166:331-335.

[22]. Barney B.M., Hitchcock Y.J., Sharma P., Shrieve D.C., Tward J.D. Overall and cause-specific survival for patients undergoing lobectomy, near-total, or total thyroidectomy for differentiated thyroid cancer. Head Neck. 2011; 33:645-649.

[23]. Kim M.J., Lee M.-C., Lee G.H., Choi H.S., Cho S.W., Kim S.-J., Lee K.E., Park Y.J., Park D.J. Extent of surgery did not affect recurrence during 7-years follow-up in papillary thyroid cancer sized 1-4 cm: Preliminary results. Clin. Endocrinol. 2017; 87:80-86.

[24]. Ji YB, Song CM, Kim D, Sung ES, Lee DW, Chung MS, Tae K. Efficacy of hemithyroidectomy in papillary thyroid carcinoma with minimal extrathyroidal extension. European Archives of OtoRhino-Laryngology 2019, Aug 276:3435-3442

[25]. Papaleontiou M., Hughes D.T., Guo C., Banerjee M., Haymart M.R. Population-based assessment of complications following surgery for thyroid cancer. J. Clin. Endocrinol. Metab. 2017; 102:2543-2551. EA, King TA, Bolton JS, Fuhrman GM. A comparison of total thyroidectomy and lobectomy in the treatment of dominant thyroid nodules. Am Surg 2002; 68:678-82.

[26]. Siassakos D, Gourgiotis S, Moustafellos P, Dimopoulos $\mathrm{N}$ and Hadjiyannakis E: Thyroid microcarcinoma during thyroidectomy. Singapore Med J 49: 23-25, 2008.

[27]. Baudin E, Travagli JP, Ropers J, et al. Microcarcinoma of the thyroid gland: the GustaveRoussy Institute experience. Cancer 1998; 83:553-9.
[28]. Pacini F., Elisei R., Capezzone M., Miccoli P., Molinaro E., Basolo F., Agate L., Bottici V., Raffaelli M., Pinchera A. Contralateral papillary thyroid cancer is frequent at completion thyroidectomy with no difference in low- and high-risk patients. Thyroid. 2001;11:877-881.

[29]. Mendelsohn A.H., Elashoff D.A., Abemayor E., St John M.A. Surgery for papillary thyroid carcinoma: Is lobectomy enough? Arch. Otolaryngol. Head Neck Surg. 2010; 136:1055-1061 Roti E, degli Uberti EC, Bondanelli $\mathrm{M}$, et al. Thyroid papillary microcarcinoma: a descriptive and meta-analysis study. Eur J Endocrinol 2008; 159:659-73.

[30]. Tuttle RM, Tala H, Shah J, et al. Estimating risk of recurrence in differentiated thyroid cancer after total thyroidectomy and radioactive iodine remnant ablation: using response to therapy variables to modify the initial risk estimates predicted by the new American Thyroid Association staging system. Thyroid 2010; 20:1341-9. 